\title{
EL POP ART INGLÉS Y SU INFLUENCIA EN EL DISEÑO INTERIOR Y LA ARQUITECTURA
}

\section{THE BRITISH POP ART AND ITS INFLUENCE IN THE INTERIOR DESIGN AND THE ARCHITECTURE}

\author{
MTRA. ILEANA AMEZCUA DÍAZ
}

Profesora de tiempo completo. Asociado B. Licenciatura de Diseño de Interiores y Ambientación. Dirección: Mariano Azuela 588

\section{RESUMEN:}

El propósito de este artículo de reflexión es abordar el movimiento del Pop Art inglés y su influencia tanto en el diseño interior como en la arquitectura; analizar los aspectos socioculturales que impactaron la forma de vivir y habitar los espacios en los años 50's y 60's del siglo pasado, décadas marcadas por cambios significativos en la sociedad relacionados con la forma de consumo, el desarrollo tecnológico, la industrialización y producción en serie. Por otra parte, se considera que fue un escenario propicio para el surgimiento del pop como vanguardia artística, en la que se dio prioridad a la investigación y experimentación plástica y tecnológica; en el que aparecieron artistas, diseñadores y arquitectos que utilizaron nuevos materiales y sistemas constructivos que les permitieron manejar un nuevo lenguaje, que aun en la actualidad resulta acorde con las costumbres, ideas y necesidades del mundo contemporáneo.

\section{PALABRAS CLAVE:}

arquitectura, consumo, contracultura, diseño interior, experimentación, habitar, innovación, otredad, vanguardia.

\section{ABSTRACT:}

This reflection article aims to talk about the British Pop art movement and its influence on both interior and architecture design, besides analyze the sociocultural aspects that impacted the way of living and inhabiting spaces in the 50 s and 60 s of the $X X$ century, those years were impacted by significant changes in society related to the form of consumption, technological development and industrialization. We also believe that those decades were the proper scenario for Pop Art rising, where priority to plastic and technological research and experimentation occurred, where artists, designers and architects applied new materials and construction systems that allowed them handle a new language

\section{KEYWORDS:}

Architecture, consumption, counterculture, interior design, experimentation, inhabit, innovation, vanguard. 


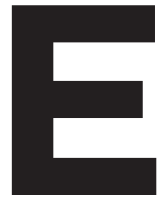
L Pop Art o Arte Pop surgió en Estados Unidos como una manifestación occidental que creció bajo la sombra de las condiciones capitalistas y tecnológicas de la sociedad industrial. Norteamérica es el centro del movimiento, con lo cual se produce la americanización de la cultura de gran parte del mundo occidental, especialmente en Europa y en específico en Inglaterra, hacia el año 1955, pero su mayor auge se manifiestó en la década de los sesenta.

El término lo puso en circulación el crítico holandés Lawrence Alloway para referirse al movimiento artístico que deriva de la abreviación de "popular art", que hace referencia al arte popular que se utilizaba en publicidad, diseño, arquitectura, carteles y revistas ilustradas, entre otros (0sterwold, 1999, p. 40). Este movimiento se convirtió en el punto de mira de los nuevos ciudadanos con derecho a voto, los jóvenes urbanos, la nueva clase media acomodada y la ambiciosa clase obrera de los países con fuerte crecimiento económico. Ya no había lugar para la tradición paternalista del buen gusto impuesto por unos pocos de clase y educación privilegiadas, gran parte de la población quería una gratificación visual inmediata, novedades y, cambios. Surgió entonces una sensibilidad visual que se denominó Pop.

Es una vanguardia artística que se inspira en la sociedad de consumo ${ }^{1}$, creando una temática directa, realista, extraída del medio ambiente urbano de las grandes ciudades, de sus aspectos sociales y culturales, accesible al público en general. “El arte pop es el resultado de un estilo de vida, es la manifestación plástica de una cultura caracterizada por la tecnología, el capitalismo, la moda y el consumismo, donde los objetos dejan de ser únicos para ser pensados como productos en serie" (Montaner, 2002, p. 86). Del mismo modo, es considerado como el arte del concepto, de la investigación plástica, del lenguaje figurativo referido a las costumbres, ideas y apariencias del mundo contemporáneo.

El Pop Art estadounidense, al igual que el británico, encontró diversos escenarios para acercarse a la población que en ese momento estaba ávida de consumir productos que reflejaran su modo de vida y su estatus social y económico; asî fue como se manifestó en la pintura, escultura, publicidad y diseño, entre otros; en los que a su vez, los personajes o estrellas del cine y la música pasaron a ser íconos populares; el artista era un elemento fundamental que se reconocía y se identificaba con la sociedad de los medios de masas; perdían su identidad individual para integrarse en una nueva identidad colectiva seguidora de esta vanguardia.

La conducta provocativa, la conmoción y la alteración de lo cotidiano, la ruptura de los tabúes y el final de la mojigate-

Sociedad de consumo. Este concepto está ligado al de economía capitalista de mercado, por tanto, sus criterios y bases culturales están regidos por ese mercado. Las personas están consideradas como la masa de consumidores a quienes se puede influir en sus deseos y crear teles de apoyo de historia universal, El pop art, reflejo de unos años turbulentos. En: http://www. cch.unam.mx/historiagenda/11/contenido/sea1.html, 3 de octubre de 2012 ría forman parte de esta contracultura. Este proceso puso en marcha la inversión de los valores en las relaciones humanas y cuestionó el tradicional reparto de papeles; la educación antiautoritaria, las nuevas estructuras profesionales, la emancipación de la mujer y la liberación sexual se desarrollaron a partir de esta "revolución cultural". La revalorización de lo trivial se efectuó a muchos niveles.

Se considera que la interacción y la integración de todas estas estructuras sociales y el artista se dio a través de una perspectiva antropológica, en la que se hizo evidente el concepto de otredad ${ }^{2}$, marcado por un nosotros nuevo, en el que el punto de convergencia fue la fusión de las necesidades cotidianas de la vida diaria de las personas, expresadas en esta nueva conceptualización del arte, la estética popular y el artista, que a través de sus obras tradujo esta fusión en una nueva vanguardia en la que se ve reflejada la sed de una sociedad doliente y carente de sentimientos profundos, que los llevó a fusionarse en las diferentes propuestas que los artistas hicieron como representaciones simbólicas de esa necesidad por encontrar, reflejar e identificarse colectivamente en su contexto social cultural y económico; al mismo tiempo, esta vanguardia mostraba una especie de sátira contra los estilos marcados en su pasado, retomándolos y acoplándolos a la búsqueda de una nueva cultura que les diera sentido de pertenencia.

De toda esta diversidad de expresiones culturales relacionadas con el Pop Art en Estados Unidos e Inglaterra, en este trabajo solo se retoma el movimiento vanguardista británico, debido a que fue en el que se marcó con mayor énfasis y trascendencia el vínculo entre el Pop Art como movimiento artístico de vanguardia con el diseño de interiores y la arquitectura.

\section{El diseño de interiores y la arquitectura bajo la óptica del Pop Art británico}

A comienzos de los años cincuentas algunos artistas e intelectuales se dieron cuenta que su cultura cada vez estaba más influenciada por los medios de masas (películas de ciencia ficción, música pop y el mundo de la imagen), junto a una apreciable consolidación del americanismo en Europa, este cambio cultural ya no concordaba con el expresivo estilo abstracto de la pasada generación de artistas en Inglaterra, representada por Henry Moore, entre otros.

Los temas generales del Pop Art eran la subcultura, la cultura popular, las imágenes de los medios de comunicación, las nuevas tecnologías, el diseño, la industria de consumo y la

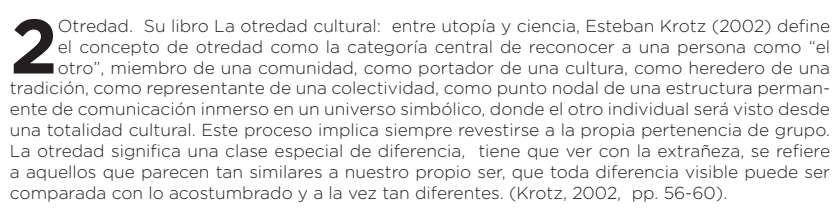


interrelación de estas manifestaciones y su influencia sobre el hombre. Así fue como en 1952 en el Instituto de Arte Contemporáneo de Londres (ICA), surgió el Independent Group, integrado por sus miembros fundadores: Eduardo Paolozzi, Richard Hamilton, profesor de diseño industrial y de interiores de esa época, el fotógrafo Henderson, el escultor William Turnbull, entre otros muchos que se dedicaban al diseño de muebles, los arquitectos Alison y Peter Smithson, los historiadores y críticos de arte Lawrence Alloway y Reyner Banham; todos ellos afirmaron su interés por la cultura urbana producida en masa; de ahí la variada temática de los actos y la prioridad por una perspectiva antropológica. Todos estos personajes empiezan a discutir en torno al impacto que la tecnología moderna y los medios de comunicación de masas estaban teniendo en la sociedad. En estos debates se derribó el concepto de que las Bellas Artes eran la cima y las equipararon al cine, a las artes populares y a las artes gráficas a raíz de esta nueva mirada y tras escuchar la necesidad de una sociedad ávida por consumir lo que el mercado le ofreciera; ahora se dejaban ver como clientes potenciales a quienes después de haber sufrido una Segunda Guerra Mundial, se sintieron acogidos e identificados por una arquitectura diferente, e inherente a ella, un diseño de interiores que entendía esa necesidad emocional adolescente expresada y reflejada en sus interiores. Como complemento de la arquitectura y el diseño de interior se unieron a estas disciplinas el diseño industrial, reflejado en objetos utilitarios, en tecnología de electrodomésticos y mobiliarios; el diseño gráfico, que se manifestaba en sus collages y murales; así como la pintura y escultura.

Uno de los más grandes exponentes de esta corriente de artistas fue Richard Hamilton, pintor y profesor de diseño de interiores en el Royal Collage of Art de 1957 a 1961, quien reveló en sus montajes su visión crítica y reveladora de las tendencias de la cultura y la sociedad contemporánea. Massey ( 1995), menciona que es considerado el artista que creó la primera obra del Arte Pop, el collage titulado “¿Qué es lo que hace a los hogares de hoy día tan diferentes, tan atractivos? ", que fue expuesto en la exposición titulada Esto es el mañana en la Whitechapel Art Gallery de Londres en 1956, la cual se convertiría en el manifiesto del arte pop británico, movimiento en el que Hamilton tuvo un papel esencial, ya que su deseo de que el arte fuera: efímero, popular, barato, producido en serie, joven, ingenioso", lo llevó a expresar una nueva concepción de arte, en un Pop culto y altamente intelectualizado.

En esta obra aparecen multitud de elementos de la cultura de masas estadounidense: una chica de revista, un culturista, un televisor, un logotipo de Ford, una portada de historieta, una aspiradora, un cartel de cine, un retrato de un antepasado centenario y un enorme chupa-chups (caramelo con palo) sostenido por el culturista como si fuese una raqueta de tenis, todo ello bajo el planeta Tierra a modo de techo (Dempsey, 2008 p. 217).

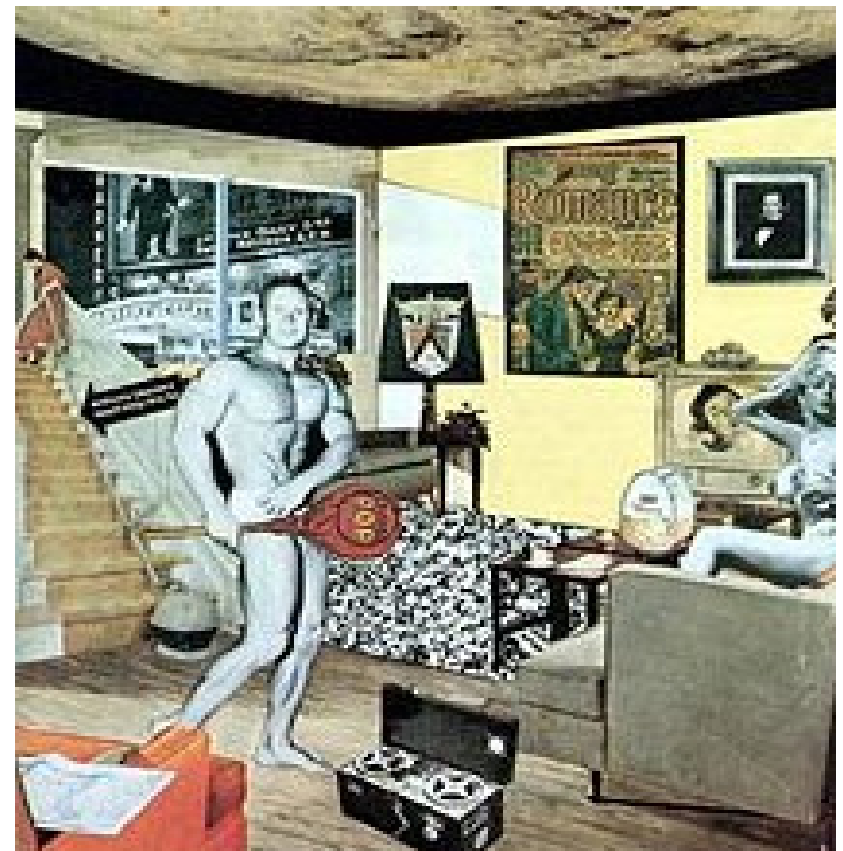

Al igual que Hamilton, muchos de sus colegas trabajaron bajo esta premisa, con lo cual se produjeron espacios que marcaron un período con un sello distintivo de vanguardia, se comenzó a formar un vínculo estrecho de integración entre las bellas artes y el interiorismo; así, los críticos Mario Amaya y George Melly ( 2012) propusieron al diseño de interiores como la alternativa preferida de la arquitectura; esta preferencia por el interiorismo se vio reforzada cuando los elementos arquitectónicos se diluyeron a medida que la habitación o lo habitable se convirtiera en un entorno, un escenario, un ambiente que provocaba en los usuarios experiencias, vivencias y emociones que les otorgaban sentido de pertenencia.

Dentro de este grupo de artistas se pueden mencionar a algunos arquitectos destacados, como la pareja de Alison y Peter Smithson, que al casarse en 1949 abrieron un estudio en Londres. La casa de Colville Place, 46 en el Soho, es una de las primeras casas que diseñaron para sí mismos. (El poder de las palabras 2014). Esta pareja de arquitectos presentaron hacia 1950 una propuesta que satisfizo y proyectó la ideali-zación del nuevo hogar moderno. La Casa del Futuro es una de las siete casas que se presentaron bajo los cánones de la modernidad, formando el "pueblo de hoy y de mañana" en la exposición de la Casa Ideal organizada por el periódico Daily Mail en 1956 (Arch Works, 2014).

Los Smithson recrearon e imaginaron cómo podría ser una casa normal dentro de 25 años y cambiaron la manera tradicional de diseñar una casa: En vez de diseñarla con un jardín alrededor, todas las habitaciones se distribuían en torno a un patio, los tabiques divisorios entre habitaciones estaban for- 

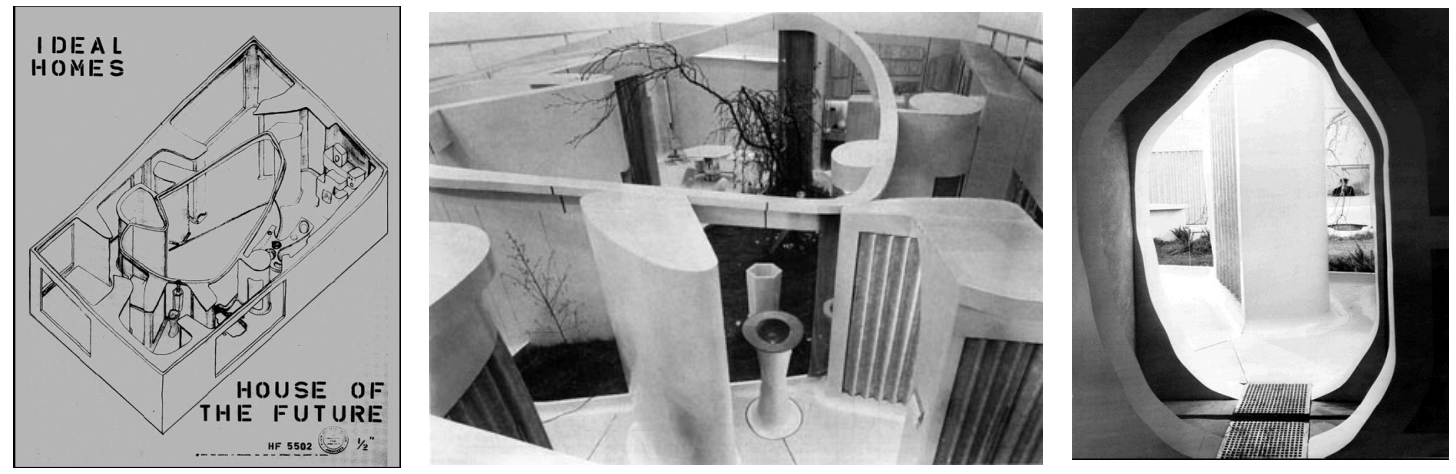

Maqueta que muestra la propuesta interior de la casa del futuro de Alison y Peter Smithson, 1956
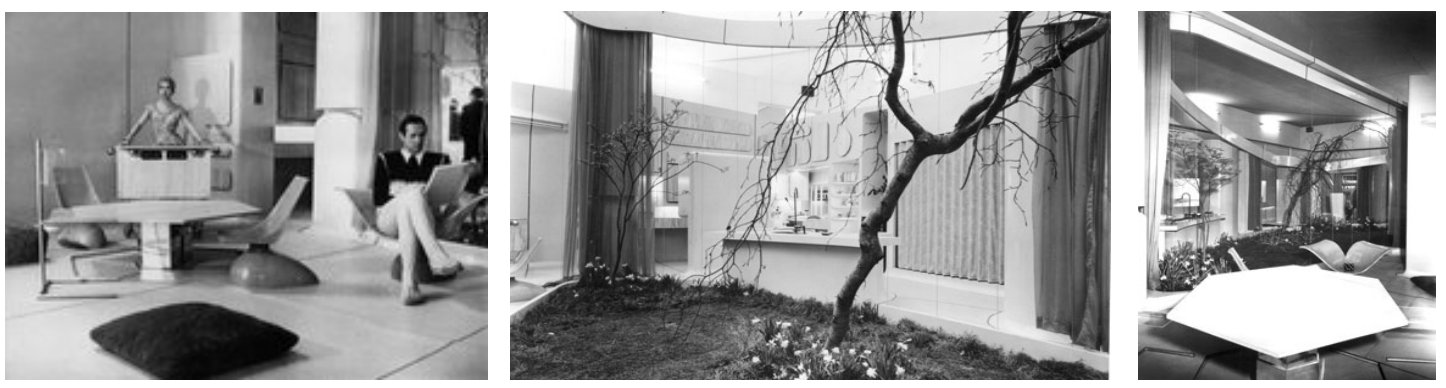

Imágenes que muestran la propuesta interior de la casa del futuro de Alison y Peter Smithson, 1956

mados por armarios y estanterías empotradas a zonas de servicio (The Desing Museum, London 2014). Se prestó una atención especial a la cocina y sus anexos. En los revestimientos de las paredes surgieron formas orgánicas con esquinas redondeadas que permiten que las habitaciones fluyan las unas en las otras. Según lo relatado por Alison Smithson, la impresión general que debe dar la casa es de glamour, la propuesta de la casa del futuro fue considerada como una pieza arquitectónica de recambio, generando con ella el estilo duradero.

Otro proyecto interesante e importante que crearon los Smithson fue la denominada "Hexehaus" o Casa de brujas, que surgió de la transformación de la casa del fabricante de muebles alemán Axel Buchhauser, con quien colaboraron los Smithson. La propuesta fue construirla sobre un bloque de estructura de madera situado en la ladera de una colina. Los Smithson fueron añadiendo ventanas o balcones articulados en cada apertura de los muros, claraboyas o varios pabellones.

Es necesario hacer la aclaración (Charlotte y Peter Fiell, 2007), que ellos no solo propusieron esta casa ecológica, sino que a su vez lanzaron una nueva tendencia ideológica, su propia visión futurista, al integrar la arquitectura a la naturaleza, y como complemento de ambas, el hombre, como parte de la ecología, entendida esta como la ciencia que estudia los hábitats de los seres vivos. El matrimonio de arquitectos transmitió en la visión de sus propuestas de vivienda conectar la casa, el entorno y el espacio. Decían los Smithson que los arquitectos deben aprender de la cultura de masas; con esta propia filosofía de su arquitectura aplicaron lecciones de los estilos en continuo cambio y de la atracción popular por el diseño arquitectónico.

La estética del recambio una fuente decisiva del nuevo diseño interior británico, con un nuevo perfil de consumidor, gracias al aumento de fuentes de trabajo y salarios dignos. Así fue como los jóvenes de entre dieciséis y veinticuatro años se convirtieron en el segmento de mercado con alto poder adquisitivo que demandaba espacios acordes con su nueva realidad, que simbolizan su nueva independencia.

En los años 70 se centraron en concursos para mostrar esas alternativas a las viviendas tradicionales; algunas de ellas fueron la rehabilitación basada en los baños, cocinas y su posición dentro de la casa; aun con ello la arquitectura de la antigua casa era respetada. En la exposición de maquetas se exhibieron casas rehabilitadas y diseñadas por ellos.

Las aportaciones que hicieron los Smithson los ubicó como figuras líderes en la arquitectura internacional y en la escena de planificación urbana en las décadas de los 50's y 60's; además de ser promotores de un enfoque intelectual pragmático, antirretórico y experimental; en 1954 formaron la escuela Hunstanton. Norwick, en Gran Bretaña, donde se fortalecieron estos valores del intelecto. De acuerdo con la precisión 

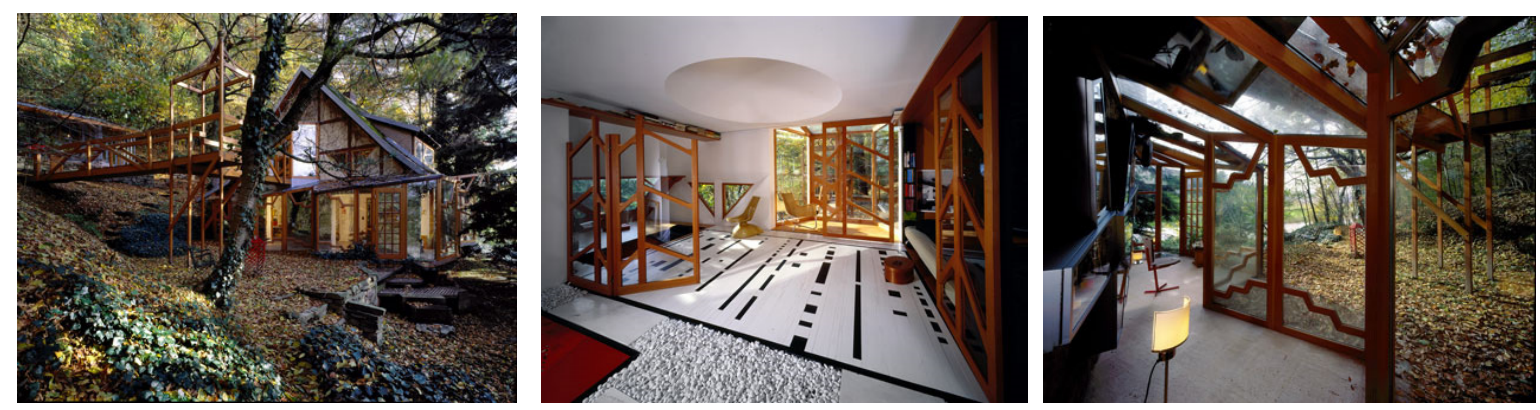

Imágenes que muestran La Casa de Brujas de los arquitectos Alison + Peter Smithson, en Alemania
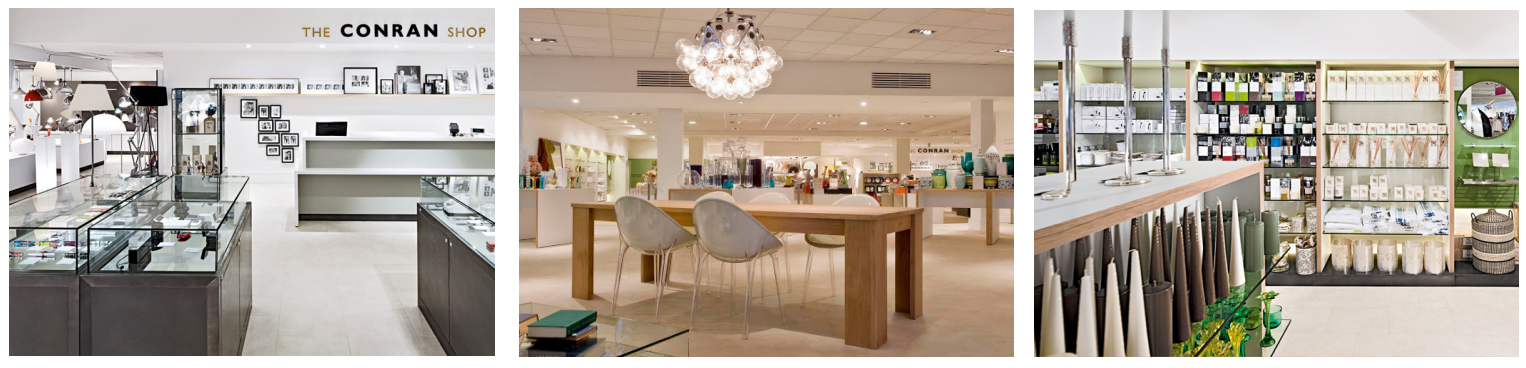

Interior de Habitat de Terence Conran, mobiliario y productos para el hogar

de Massey (1995), al liderazgo inicial de los británicos Alison y Peter Smithson y el holandés Aldo Van Eyck se unieron el peso de Bakema (también holandés), Ralf Erskine (sueco) y Woods (norteamericano), por encima de la presencia de José Antonio Coderch (español), Kandilis (griego) y Pancho Guedes portugués (Massey, 1995, pp. 171 - 175).

En la Conferencia Internacional de Arquitectos Modernos destacó Douglas Fisher, diseñador londinense, quien, entre otros trabajos, diseñó la Góndola, en Wigmoore Street, el Mocamba y el Cubano en Brompton Road; en este último destacó su creatividad Pop al proponer mesas revestidas de plástico brillante y perfiles de aluminio, utilizó mobiliario popular contemporáneo,y destacaron los muros de piedra o su representación en papel tapiz.

El inglés Terence Conran, diseñador de interiores, se encargó del diseño de la tienda bazar en Knightsbridge en 1957 para la diseñadora de modas Mary Quant, en la que destacaría la innovación en vestimenta femenina con la minifalda. Según la información encontrada en Osterwold (1999), hubo influencia del Pop Art en espacios de diversos géneros en los que él trabajó, como: el habitacional, el comercial, hasta los más simples detalles, como vasijas o libreros. Se le consi-deró un visionario en el diseño de interiores; además por su inclinación hacia el diseño industrial. Después de hacer un viaje a Japón regresó inspirado por este, cuestionándose lo gris que parecía ese país; con cuya analogía hizo su propuesta de diseño interior en restaurantes y vivienda debido a lo cual se convirtió en uno de los grandes exponentes del diseño inte- rior (Osterwold, 1999).

Después de adquirir diferentes experiencias ambientales en sus viajes concluyó que el hábitat necesita color en sus interiores; mismos que marcarían su propio espacio y su propio hogar; sostuvo que el diseño interior no debería tomarse como un estilo global y que para ofrecer el mejor diseño habría primero que estudiar el mercado, como lo fue en el Pop Art; también expresó que el diseño inteligente proviene del conocimiento, de la experiencia, de la educación, aporta calidad de vida y que los objetos bien diseñados hacen a la gente más feliz y provocan que tengan una mejor vida (Coll, 2012).

El diseño de una casa consistía en algo más que escoger unos muebles; el diseño se aborda desde una amplia perspectiva, en la que incluye su intervención en la fontanería, los suelos, la iluminación y los acabados, que tocan aspectos concretos del interiorismo; su finalidad es ofrecer el máximo confort para que el habitante no utilizara sino que habitara el espacio con la perspectiva de diseño integral (Massey, 1995, p. 174).

Bárbara Hulanicki en 1964 abrió la primera tienda en High Street de Kensington, en Londres: la tienda Biba, que distinguió los interiores de manera muy peculiar: con poca iluminación, con música Pop a todo volumen, decorada en tonos oscuros, adicionalmente se usaron pies victorianos de madera curvada para colgar la ropa en venta, plumas de avestruz y vasos decimonónicos que acentuaban el concepto de atmósfera decadente, alusivo, a lo que en la época pop se manejara, como una omisión de las costumbres sociales; con el tiempo, 

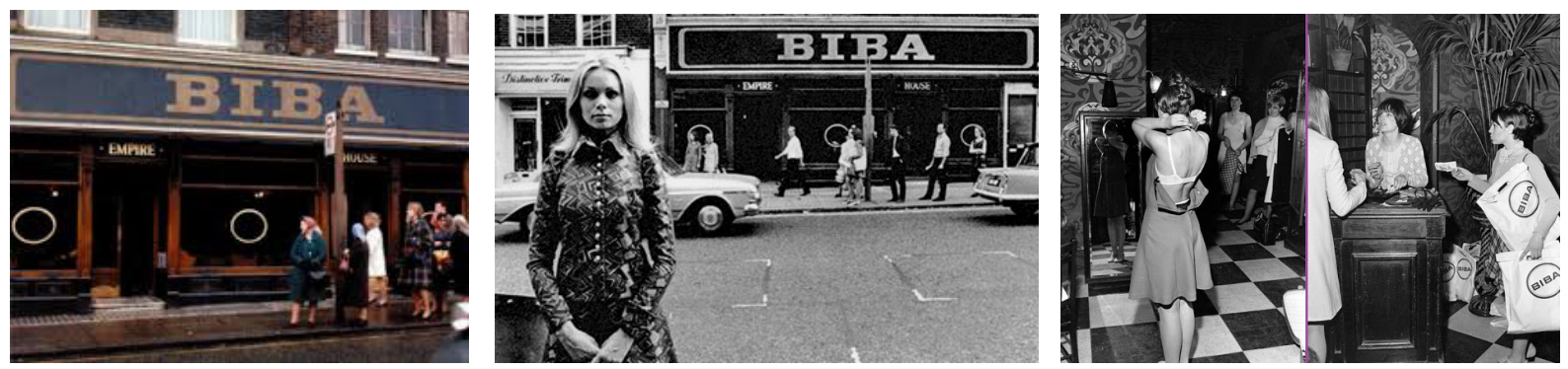

La tienda Biba diseñada por Bárbara Hulanicki, uno de los primeros almacenes multifuncionales
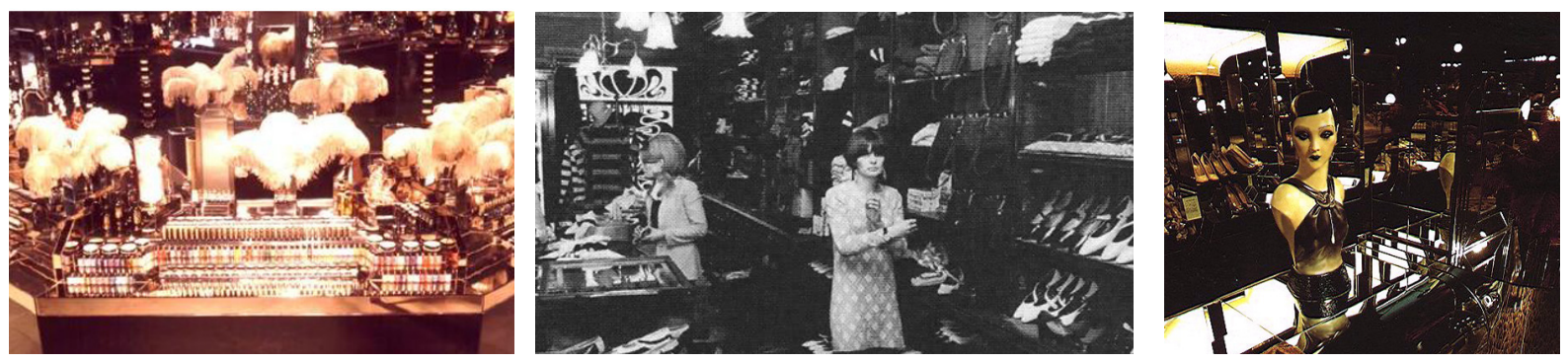

Imágenes del interior del almacén Biba, fuente de inspiración para las grandes tiendas departamentales

la tienda "Biba" marcó un estilo de vida y fue el detonador que señaló el potencial de un almacén multifuncional, llamada entonces "máquina de sueños".

Después de ver consolidado su almacén integró en la azotea de este, la innovación de un jardín con un estanque lleno de patos, flamencos y pingüinos; a este espacio lleno de glamour acudían el jet set y la gente más importante de la época; por último, incorporó una sala "the rainbow room upstairs", en la que celebraron fiestas y actuaciones, como la de "New York Dolls" (My Best Life: GapYah@stop, 2014). Parece que parte del éxito de la tienda "Biba", tuvo que ver con esa compleja integración de espacios interiores y exteriores.

La diversidad en los ambientes, el manejo del espacio efímero, que a su vez comprendían a la perfección no solo a la sociedad consumista, sino a una sociedad atraída por pertenecer a un grupo social o a una elite que se identificaban entre sí, con los mismos gustos, con sentido de pertenencia y concentrados en el lugar de boga.

Finalmente la tienda Biba se trasladó a la antigua tienda Art-Decó Derry and Tom a principios de los setentas, con interiores retro diseñados con otra tendencia por escenógrafos del cine.

Los precursores del Pop Art en Gran Bretaña fueron David Hockney y Allen Jones, ambos, al igual que otros artistas, tomaron la cultura en masas como inspiración y participaron en la exposición llamada "Cuatro ambientes para nuevos realistas". Otro que destacó fue Claes Oldenburg, quien a pesar de ser escultor del pop, diseñó un dormitorio que hacía alusión a las sociedad con estas características, con sábanas blancas, de vinilo satinado y un sofá de imitación piel de cebra con una falsa piel de leopardo, echada sobre él (Colección on line, Museo Guggenheim, 2014).

El diseñador de interiores francés Oliver Mourgue en 1964 creó conjuntos futuristas para la película "2001: Una odisea del espacio"; la equipó con asientos bajos y curvos en exageradas formas amebianas, con colores brillantes e incluso fluorescentes, que se extendieron desordenadamente por techos, paredes, puertas y suelos. En 1966 en Gran Bretaña destacó La Chaise longe de Djinn, de suaves curvas. Para el diseño de interiores fue básica su dimensión social y la complejidad del mismo.

En 1968 se mostró el rechazo por la tecnología; ahora la cultura se tornaba a una sociedad con conciencia política y espiritual, nacieron los hippies rechazando los valores convencionales de occidente, y como una expresión de sus nuevas convicciones transformaron el concepto del hogar; mismo que se mostró en conjunto e itinerante, en caravanas o tiendas.

Los objetos naturales se integraron en las nuevas tendencias, principalmente de la india, iluminaron con velas y fuegos reales, el papel tapiz era dibujado a mano, es decir, donde antes se generó un espacio divertido, posteriormente Este se tornó en un espacio matizado con una propia conciencia política.

Entre todo este movimiento nuevamente se distinguió Terence Conran, quien en 1964 fundó en Londres la primera cadena comercial de mobiliario y hogar con productos de estilo para la 
emergente clase media llamada Hábitat, donde presentó toda una tendencia en decoración con objetos naturales, muebles de playa, interiores en blanco, pisos neutros y piedra natural.

La Arquitectura recuperó en estas últimas décadas el diálogo con su propia historia, la forma de su relación con la ciudad, la conciencia de su esencialidad ligada a la forma y la voluntad de ser expresiva mediante el lenguaje ambiental reconocido en el diseño interior.

\section{CONCLUSIÓN}

Después de realizado este trabajo de reflexión sobre la influencia del Pop Art en la arquitectura y el diseño interior de los espacios habitados por la sociedad inglesa en un momento histórico de fractura, de posguerra, pero también de transiciones que determinaron el rumbo de estas disciplinas, a mediados del siglo $X X$, así como su evolución, desarrollo e impacto en el proceso de industrialización de las sociedades occidentales actuales, se comprobó que este progreso fue escenario propicio para que surgieran una serie de prácticas en las grandes ciudades, donde la relación entre la tecnología y el hombre rige lo cotidiano.

Así, bajo este contexto, se considera que el Pop Art, más que un movimiento, una corriente, una escuela artística o un estilo, fue un fenómeno cultural de enorme repercusión internacional que se extendió desde mediados de los cincuenta hasta principios de los setenta del siglo pasado; cuyos alcances fueron puntuales dentro y fuera de la sociedad en que se manifestaron.

El mundo Pop rechazaba la estética clásica, que concebía el arte como una representación elitista, y lo cambia por una concepción más fluida, menos rigorizante, fuera de la imposición jerárquica del valor estético tradicional; así es como surgen espacios accesibles que eran comprendidos y aceptados fácilmente por sus usuarios; estos estaban llenos de colores brillantes, formas orgánicas y texturas ópticas y táctiles que evocaban sensaciones de libertad y glamour que eran rápidamente explotadas por los medios de comunicación. Así es como Wilson (1985) describe que inicialmente las obras de los artistas pop fueron recibidas como si se tratara de un chiste de mal gusto y se acostumbraron a escuchar que dijeran de ellos que no eran otra cosa que artistas vulgares, sensacionalistas y antiestéticos que usaban múltiples colores referencias y efectos que evocaban la libertad de imaginación en formas gráficas complejas.

Encajaban las descalificaciones exhibiendo ese género, ya que sabían que si los demás protestaban en su contra era debido a que no iban por tan mal camino. Efectivamente, poco a poco sus nombres de pila se fueron identificando con los inventores de un fenómeno que respondía directamente a la vida consumista, a su carácter integrador, democrático y no discriminatorio, a pesar de que como artistas fueran conscien- tes de que al menos un tipo de discriminación era inevitable: estaban obligados a elegir qué imágenes sí y qué imágenes no, saldrían en representación del mundo de los consumidores reales.

Uno de los aspectos importantes en esta reflexión es que "Pop", más que ser un sinónimo de "popular", es una voz (un sonido, un concepto), con distintos derechos y semiótica lingüística, que tuvo una trascendencia y una repercusión más allá de lo "popular". "El Pop art no fue un arte popular", como reconoció el artista pop inglés Richard Hamilton, porque estaba hecho por expertos profesionales, altamente cualificados para un público masivo. Robert Hughes, el crítico de arte de la revista Times desde 1970 y una de las voces más escuchadas del mundo en materia de arte en general y de arte norteamericano en particular, le añadió el siguiente corolario: El Pop Art no se hizo para la gente, sino que se le hizo a la gente.

Por otra parte, resultó interesante encontrar personajes en el diseño de interiores del Pop art, ya que este fue el detonador para que cada diseñador explotara y explorara su visión en este género interiorista, dejando diferentes y valiosas aportaciones, que han marcado definitivamente las tendencias que ya han pasado de generación en generación hasta convertirse en parte de la vida cotidiana; una de ellas, Barbara Hularicki con su tienda Biba, llegando al posible punto de ser inspiración de cadenas de tiendas departamentales que hoy conocemos como "Liverpool", "Palacio de Hierro" o "C Penny", entre otras; que continúan identificando a una clase elitista. Otro detonador fue el impacto que trajo consigo el haber ideado una terraza en la azotea; misma que ahora no solo vemos en almacenes departamentales sino en hoteles de gran turismo; en fin, lo que ella aportó ha servido como la puerta hacia todo un abanico de posibilidades dentro del diseño de interiores.

El hombre visionario de Terence Conran quién hasta nuestros días continúa vigente en el mercado cambiante y de consumo que sigue distinguiendo a algunos países; tratando de entender ese pensamiento creativo y atinado, hizo lo que a algunos diseñadores les falta hacer hoy en día: primero tener una postura que denote carácter y firmeza de pensamiento; segundo, observar lo que ocurre con la sociedad para resolver certeramente sus necesidades y por último, escuchar lo que le aqueja a esta misma, para entonces ofrecer ambientes que satisfagan dicha necesidad espacial-emocional. Claro que no se trata de globalizar una tendencia o una moda, sino de identificar una cultura a través de los ambientes interiores y su contexto sociocultural. 


\section{REFERENCIAS BIBLIOGRÁFICAS}

Amaya, M. \& Melly, G. , Revolt into Style; The Pop Arts, e book. London: Faber and Faber Ltd.

Charlotte \& Fiell, P. (2007). Design Handbook, Concepto, Materiales, Estilos. Italia, Taschen.

Dempsey, A. (2008). Estilos, Escuelas y Movimientos. España, Blume.

Krotz, E. (2002). La otredad cultural entre utopía y ciencia. México: UAM, FCE.

Massey, A. (1995). El Diseño Interior en el siglo XX. Barcelona: Ediciones Destino.

Montaner, J. Ma. (2002). Las Formas del Siglo XX. Barcelona: Editorial Gustavo Gili.

Osterwold, T. ( 1999). Pop Ar, Singapur: Taschen.

Wilson, S. (1985). El Arte Pop. España: Editorial Labor.

\section{Sitios web}

Arch Works, (2014, 21 de marzo), Magazine en línea de divulgación de arquitectura, disponible en: http://posthabitat.blogspot.com/2006/10/alison-and-peter-smithson-from-house.html.

La arquitectura de la segunda mitad del siglo XX. (2008, 8 de octubre), Sección cultura, El País, Barcelona. Disponible en: http://cultura.elpais.com/tag/arquitectura/a/307.

Colección on line, Museo Guggenheim (2014, 10 de marzo). Disponible en:: http://www.guggenheimcollection. org/site/artist_bio_121.html.

Coll, A. (2012). Arquine, revista electrónica, (2014, 25 de marzo), Disponible en: http://www.arquine.com/blog/terence-conran-en-el-design-museum/

My Best Life: GapYah @ Stop (2014, 23 de marzo). Disponible en: http://mybestlifegapyahstopathome.blogspot. $\mathrm{mx} /$.

El poder de la palabra. (2014, 22 de marzo). Biografías de arquitectos y sus obras. Disponible: http://www. epdlp.com/arquitecto.php?id=155.

The Design Museum, London. (2014, 23 de marzo). Exhibición internacional del trabajo de Alison y Peter Smithson en 2004. Disponible: http://www.designmuseum.org/ design/alison-peter-smithson.

The Design Museum, London (2014, 23 de marzo) Exhibición internacional del trabajo de Alison y Peter Smithson en 2004. Disponible en: http://www.designmuseum.org/_entry/4468?style=design_image_popup.

\section{Fuentes de imágenes}

Casa del futuro, http://es.wikiarquitectura.com/index.php/Casa_ del_Futuro

Casa de brujas Alison \& Peter Smithson, http://es.wikiarquitectu-
ra.com/index.php/Hexenhaus

Collage de Richard Hamilton, www.artehistoria.jcyl.es/v2/contextos/5534.html

Conran Shop, revisión interior Habitat, http://www.inshop. es/2011/06/habitat-triste-despedida.html

Diseños de Terence Conran, http://www.interioresminimalistas. com/2011/12/15/el-design-museum-london-celebralos-80-anos-de-terence-conran-con

Fachada tienda BIBA, http://girlsaremadeofsugar.blogspot. $\mathrm{mx} / 2009 / 04 /$ bibauna-tienda-de-ensueno.html

Interiores tienda BIBA, http://www.trendipia.com/el-abc-de-lamoda-biba-shop-la-tienda-de-los-60s

FORMA DE CITAR ESTE ARTÍCULO

Amezcua Díaz, lleana (2013). El pop art inglés y su influencia en el diseño interior y la arquitectura. Revista Arte y Diseño Facultad de Arquitectura, Arte y Diseño, Universidad Autónoma del Caribe, BarranquiIla. ISSN 1692- 8555 Vol. 11 (N.2) PP. 15 - 22 